\title{
Limites da intervenção do Ministério Público nas políticas públicas de promoção de Direitos Humanos no Brasil
}

\author{
Limits of Public Attorney's Office intervention in the promotion of \\ human rights' policies in Brazil
}

\section{Rodrigo Stumpf González}

\section{Resumo}

Este texto analisa como o processo de judicialização de políticas públicas relacionadas à promoção dos direitos humanos tem permitido um maior protagonismo do Ministério Público. Primeiramente, é apresentada a evolução da concepção moderna de direitos humanos e sua transformação em direitos subjetivos, que podem ser demandados judicialmente, com a atuação do Ministério Público. Em seguida são discutidos limites e contradiçôes nesta atuação. Conclui-se pela necessidade de encontrar um equilíbrio baseado no diálogo com a sociedade e na tolerância para que a intervenção nas políticas públicas possa ser efetiva e eficaz.

\section{Palavras-chave}

Ministério Público; Políticas Públicas; Direitos Humanos.

\section{Abstract}

This text discusses how the judicial analysis of humans right's public policies permited a broader intervention from Public Attorney's Office. First is presented the evolution of the modern view of humans rights and its changing in subjetive rights that can be judicially demanded by Public Attorney's Office. After are discussed the limits and contradictions carried by these actions. The conclusions point the need of an equilibrium based in dialog with the society and tolerance, so the intervention in public policies could be efetive and eficace.

\section{Keywords}

State; Government; Public Policies; Public Administration. 


\section{Introdução}

$\mathrm{Na}$ última década e meia cresceu exponencialmente a preocupação, tanto no mundo acadêmico como no mundo real, com o fenômeno que foi denominado de judicialização da política (VIANNA, 1999). Apresentado inicialmente como um busca da intervenção do Judiciário para decidir questóes relativas às disputas da política institucional, transcendeu estes limites para incluir a busca de soluçóes no sistema judicial de problemas cotidianos relacionados à execução das políticas públicas e a garantia de direitos sociais básicos (LOPES, 2005). Cada vez mais o debate sobre a concretizaçáo dos direitos humanos deixa de ser tratado como uma relação entre indivíduo, sociedade e Estado, representado nos Poderes Executivo e Legislativo, para incluir o Ministério Público e o Poder Judiciário.

Textos do mundo jurídico que discutem o tema dos direitos humanos frequentemente se centram na discussão teórico filosófica dos seus fundamentos, ou da positivação de direitos tornados "direitos fundamentais" na previsão abstrata das leis. No entanto, como observou Bobbio (1992) em outro momento, basta olhar em volta para ver violaçóes dos direitos humanos. Portanto, torna-se necessária uma abordagem que leve em conta o mundo real e a situaçáo em que se encontram os agentes que lutam para que as previsóes abstratas se concretizem.

Este trabalho, faz inicialmente uma análise da evolução histórica da concepção de Direitos Humanos até a atualidade, como pano de fundo para discutir sua situação no Brasil, particularmente no uso de políticas públicas para a promoção de direitos humanos e os limites de conveniência política e de eficácia da judicialização, através da intervenção do Ministério Público, como meio de implementação destas políticas no Brasil.

\section{Direitos Humanos, uma longa história}

Embora seja tema amplamente discutido, ainda podemos encontrar discórdia sobre conceito e alcance dos direitos humanos (PEREZ LUÑO, 1995). Este debate é alimentado pela mudança de conjuntura política e de concepçóes de mundo dominantes. Encontramos desde a antiguidade, na formação de religiốes monoteístas, como a cristâ, a judaica, a budista e a muçulmana, o desenvolvimento da atribuição de direitos naturais, inerentes ao ser humano, por ser resultado da criaçáo divina. Estas concepçôes, no entanto, conviveram ou até mesmo serviram de justificação para guerras e escravidão, podendo ser citados os casos das Cruzadas e a conquista do continente americano pelos europeus como exemplos mais sangrentos e marcantes (COMPARATO, 1999). 
O racionalismo liberal parecia ter encontrado uma outra resposta contra estas violaçóes. O ideal de "Direitos do Homem", encontrado nos movimentos revolucionários do século XVIII proclamaram uma igualdade do ser humano, fazendo da liberdade e da tolerância os elementos centrais da vida em sociedade, com regras criadas pelo contrato social (PECES-BARBA, 1993; ARENDT, 1994).

Porém o surgimento da sociedade industrial contemporânea apontou limites para esta situaçáo de liberdade associada à igualdade formal perante as leis, com a aceitação de uma desigualdade naturalizada como consequência da divisão social do trabalho e da propriedade dos meios de produçáo. Contudo o ideal liberal de direitos do homem não naufragou apenas pela divisão da sociedade em classes ou pela emergência do capitalismo. Embora para alguns a expressão "Direitos do Homem" fosse utilizada no sentido do termo "Homem" compreender toda a espécie humana, na prática se negava este reconhecimento às mulheres ou aos seres humanos que não compartilhavam da cultura e da ausência de melanina dos povos europeus, justificando o racismo, o colonialismo e a manutenção da escravidão em dois dos maiores países da América.

A teoria contratualista, propondo a regulaçáo contratual do exercício do poder como forma de domesticá-lo, será a raiz para os textos constitucionais. Estes servirão não apenas para definir a estrutura e os limites dos poderes do Estado, mas também para hierarquizar e definir concretamente quais direitos os homens têm ou não, evitando a manutenção da cláusula aberta jusnaturalista, que permitia que setores não contemplados da sociedade considerassem seus próprios interesses como direitos naturais (PEREZ LUÑO, 1995).

O constitucionalismo foi o pai da ideia de direitos fundamentais (se alguns são fundamentais é porque outros não o são e estão em posição inferior) e do positivismo jurídico. A realidade acabou dando razão à crítica de Edmund Burke à Declaração de Direitos do Homem e do Cidadão, que segundo ele tratava-se apenas dos direitos do homem francês ${ }^{1}$ (BURKE, 1984). O mesmo ceticismo foi compartilhado por Bentham (1962), ao afirmar que a fome não é pão ${ }^{2}$.

\footnotetext{
${ }^{1}$ Texto que efetivamente foi incorporado depois à constituição francesa.

${ }^{2}$ In proportion to the want of happiness resulting from the want of rights, a reason exists for wishing that there were such things as rights. But reasons for wishing there were such things as rights, are not rights; - a reason for wishing that a certain right were established, is not that right - want is not supply - hunger is not bread. Jeremy Bentham, Critique of the Doctrine of Inalienable, Natural Rights (BENTHAM, 1962, p. 75).
} 
Esta concepção é realmente cativante. Uma definição concreta de direitos em uma lei escrita, de valor superior às demais seria uma garantia contra os abusos dos governantes. O Estado de Direito seria a forma civilizada de acabar com a opressão sobre os indivíduos. E mais, na esteira de uma reaçáo moderada ao movimento socialista revolucionário da segunda metade do século XIX, passou a se crer que as constituições são o local adequado não só para definir a proteção do indivíduo contra o Estado, mas também para diminuir as desigualdades sociais, reconhecendo direitos de fruição dos bens sociais

É irônico, se não trágico, o fato de que a mesma constituição alemã, da República de Weimar, tenha sido uma das primeiras a incluir a proteção de direitos dos trabalhadores e ao mesmo tempo fosse o texto vigente na ascensão de Adolf Hitler ao governo alemão nos anos 30. O resultado da II Guerra colocou em dúvida a suficiência da proteção da legislação nacional para a proteção não só das pessoas dentro do próprio país onde vivem, mas também dos povos vizinhos (ARENDT, 1976).

A soluçáo encontrada foi aplicar ao mundo a mesma teoria que os contratualistas propuseram para os Estado Europeus dos séculos XVII e XVIII: um contrato social, constituindo uma sociedade internacional que garantisse a convivência pacífica. A receita contra a barbárie é o direito internacional. E como um ramo privilegiado deste, surgiram os direitos humanos ${ }^{3}$.

Organização das Naçóes Unidas foi criada em 1945 como resposta à guerra. E sob a égide desta foi construído um sistema complexo de documentos e agências internacionais, iniciado pela Declaraçáo Universal dos Direitos Humanos em 1948 e complementado por inúmeros tratados e convençôes, cada um com sua respectiva estrutura de acompanhamento. Além dos instrumentos convencionais nos últimos anos foram criados o Alto Comissariado da ONU para os Direitos Humanos e mais recentemente a Comissão de Direitos Humanos foi transformada em Conselho, elevando seu status dentro da instituição (TRINDADE, 1997).

Nos países da Europa ocidental a pressão organizada dos sindicatos de trabalhadores e dos partidos políticos criados a partir de sua mobilização, muitos dos quais passam a ganhar eleiçóes e ocupar o governo, associada ao temor com o

\footnotetext{
3 Termo que se tornou comum pela difusão da versão inglesa da Declaração Universal dos Direitos Humanos, que adota este termo - Human Rights - por pressão da representante norte-americana na comissão de redação, Eleanor Roosevelt. A versão oficial francesa segue a tradição da declaração da revolução francesa - Droits de L'Homme (GONZÁLEZ, 1994).
} 
crescimento dos partidos comunistas ou a ameaça do bloco soviético, leva à transformaçáo das estruturas de Estado, que passa a se responsabilizar pelo bem-estar dos cidadáos, mantendo uma economia de mercado capitalista, transformada pelo keynesianismo, testado já de forma insuspeita nos sucessivos governos de Franklin D. Roosevelt nos anos 30.

O Estado de Bem-Estar das economias desenvolvidas da Europa conseguiu sobreviver, ainda que com alguns apertos e transformaçôes, às diversas crises das últimas décadas. $\mathrm{O}$ mesmo não pode se dizer do modelo de socialismo soviético, que praticamente desapareceu juntamente com a própria União Soviética no início dos anos 90. Sem o fantasma do socialismo a rondar como uma alternativa pelos países mais pobres dos cinco continentes, algumas mudanças importantes foram verificadas nos discursos políticos e econômicos.

O fim da Guerra Fria permitiu o fim de uma disputa entre duas concepções de precedência sobre os direitos humanos, que levaram a segmentaçáo de dois Pactos Internacionais de Direitos Humanos, ao invés de um previamente previsto: um para os direitos civis e políticos, preferido pelo bloco ocidental, liderado pelos EUA e outro de direitos econômicos, sociais e culturais, preferido pela URSS.

O marco desta passagem foi a II Conferência Internacional de Direitos Humanos, promovida pela ONU, em Viena, em 1993. E, seguindo uma tendência já encontrada na Conferência sobre Meio Ambiente, a Rio 92, ampliou o papel de organizaçóes não governamentais nos debates. $\mathrm{O}$ grande resultado foi a declaração de dois princípios básicos para a aplicação dos direitos humanos: a universalidade e a indivisibilidade (TRINDADE, 1997).

A proposição da indivisibilidade já havia aparecido timidamente no relatório final da I Conferência de Direitos Humanos realizada em Teerã, em 1968, mas a concepção de geraçóes subsequentes de direitos ou a precedência de uns sobre outros impediu seu desenvolvimento.

A proposição de universalidade, embora mantida no relatório de Viena, já não representa o acordo de 1948. As divergências na formulação da Declaração Universal se davam na ênfase a direitos individuais ou sociais, mas ambas as correntes dominantes eram tributárias dos ideais iluminismo, defendendo uma perspectiva de universalidade.

Em Viena este consenso já não existia, sendo atacado, por um lado, por concepçôes antiocidentais, representadas por grupos religiosos do terceiro mundo, que criticam o modelo de 1948 como eurocentrista. Por outro lado, minorias ou 
grupos identitários dentro dos países desenvolvidos, que veem no modelo iluminista a representação de uma dominação branca, heterossexual e masculina, que sob o manto da universalidade proclama seus valores, excluindo outras identidades (GONZÁLEZ, 2007).

Se como concepção de Direitos Humanos a inexistência de prioridade de determinados direitos humanos sobre outros e sua interdependência é um grande avanço, por outro lado este discurso é construído pelos defensores de direitos humanos - diplomatas, membros de organizaçóes não governamentais, entre outros, paralelamente à sua deslegitimação por parte dos agentes dominantes no campo econômico.

Com o fim do socialismo soviético e a crescente dificuldade dos países pobres pagarem sua dívida externa, o modelo defendido pelos organismos econômicos internacionais, como Banco Mundial e Fundo Monetário Internacional, significava o abandono das experiências incipientes de programas sociais de cobertura universal nestes países ou mesmo a condenação do papel desenvolvimentista do Estado. $\mathrm{O}$ ideário defendido desde os anos 40 como alternativa ao keynesianismo por economistas como Milton Friedman e filósofos como Friedrich Hayek, de retornar a princípios básicos do liberalismo econômico clássico recebeu o nome de Neoliberalismo.

Nos países europeus, que nos anos 50 criaram Estados de Bem-Estar, a tentativa de aplicação de medidas de caráter neoliberal, como privatizaçóes e redução da cobertura de programas sociais, foi freada em seus efeitos pela mobilização da sociedade. Um exemplo direto foi verificado a poucos meses, quando manifestaçóes de rua e greves lideradas por jovens na França levaram à revogação de uma lei que facilitava a demissão de jovens sob o argumento de facilitar sua contratação.

Em países que não contavam com a mesma base social, o resultado é um retorno às concepçôes de direitos do século XVIII - liberdades do indivíduo perante o Estado e aquisiçáo de bens ou serviços no mercado.

Como se não bastasse a aplicação de medidas que diminuíram a capacidade dos Estados de prover benefícios diretos à população, na última década ocorreu uma revoluçáo tecnológica que alterou processos produtivos e a velocidade da comunicação. Entre os resultados, a fragmentação da produção industrial entre diversos países, a volatilidade do capital, dando maior importância ao capital financeiro frente ao investimento em produção e o aumento do abismo entre ricos e pobres, uma vez que mesmo aplicadas as reformas neoliberais, em muitos casos estas 
foram inúteis e os recursos adquiridos pela venda de patrimônio público desapareceu nas tentativas de enfrentar crises cambiais (como no caso da Argentina).

E culminando a mudança de panorama, a realização de atentados terroristas contra os EUA serviu de pretexto para a adoção de uma política de unilateralismo pelo governo deste país, ignorando e enfraquecendo a ONU, praticamente congelando iniciativas no campo dos Direitos Humanos, como o Tribunal Penal Internacional (GONZÁLEZ, 2007). Ao mesmo tempo, o Governo dos EUA, com apoio de alguns aliados, torna-se ao mesmo tempo um violador de direitos humanos e um defensor de medidas restritivas da liberdade, como vigilância sobre pessoas e correspondências, sob o argumento da autoproteçáo, pressionando outros países a adotar medidas semelhantes.

\section{A situação atual dos Direitos Humanos}

A retomada desta trajetória nos permite distinguir alguns dos elementos que configuram as concepçóes atuais de direitos humanos e os desafios na sua defesa.

1. Do ponto de vista filosófico prepondera uma concepção de direitos humanos baseada na idéia de "dignidade humana", cujo fundamento é buscado em concepçôes religiosas, como o cristianismo, ou em uma vertente ética baseada em Kant.

2. A estas concepçóes que dáo base ao princípio da universalidade se soma a defesa da interdependência entre os diversos direitos individuais e coletivos, sob o conceito de indivisibilidade.

3. Estas concepções são enfraquecidas e encontram-se sob a crítica, do multiculturalismo e do relativismo cultural, que rejeitam a universalidade absoluta, de concepçôes econômicas, como o Neoliberalismo e da perspectiva da ordem internacional como a Doutrina Bush (ou sua atualização com Trump) sobre a segurança internacional, que enfraquecem a indivisibilidade, colocando determinados direitos ou interesses acima dos demais.

4. Os instrumentos de proteção construídos ao longo do último século constitucionalização no espaço interno e tratados e convençôes no espaço internacional, tornam-se reféns desta conjuntura, seja pela pura e simples retirada de direitos através de reformas constitucionais, pela deslegitimaçáo dos organismos internacionais, com políticas unilaterais das grandes potências, seja pela construção de interpretaçôes que justificam a impossibilidade de garantir a totalidade dos direitos no presente. 
É dentro deste contexto que devemos analisar a situação dos direitos humanos e sua possibilidade de efetivação no Brasil, o que será discutido a seguir.

\section{E nós com isto?}

Como fica a situação do Brasil em relação à evolução da conjuntura internacional dos Direitos Humanos? Particularmente nas últimas duas décadas esta tem um grande peso na definição de nosso comportamento interno (GONZÁLEZ, 2010; GONZÁLEZ e LENTZ, 2012.)

A relaçáo do Estado brasileiro com a questáo dos direitos humanos, desde sua independência, tem sido dúbia, marcada geralmente por uma incorporação fácil do discurso dos direitos humanos como mera retórica, sem consequências diretas na prática política. Um primeiro sinal desta inconsistência está na Constituição de 1824, que incorpora um capítulo sobre direitos e garantias individuais, mas silencia sobre a manutenção de uma economia escravocrata.

Outro indicativo se dá no fato que nos mesmos períodos em que ocorre o reconhecimento de inúmeros direitos sociais estes benefícios são acompanhados de violaçóes de direitos civis e políticos por governos ditatoriais, como é o caso do Estado Novo. Este padrão levou José Murilo de Carvalho (2001) a propor que no Brasil o reconhecimento dos direitos sociais precede o reconhecimento dos direitos civis.

As mazelas do autoritarismo, de um Estado que precederia a existência da sociedade foram enfrentadas com a esperança de uma mudança nos anos 1980. O receptáculo da expectativa destas transformaçôes foi a Assembleia Nacional Constituinte, resultando na Constituição Federal de 1988.

Nela continua-se a encontrar elementos de retórica. O Art. $1^{\circ}$ fala na existência de um "Estado Democrático de Direito". Nos momentos em que o Estado não é simplesmente inexistente perante a população, ele frequentemente não é democrático e tampouco de Direito.

Parece que chegamos tarde no banquete e só restaram os pratos vazios. $\mathrm{Na}$ esfera internacional, o Brasil aderiu aos principais tratados e convençôes de Direitos Humanos, reconhece a competência de tribunais internacionais, participa ativamente de conferências, tornando-se um membro pleno do sistema internacional de proteção aos Direitos Humanos, nos anos 90 (PIOVESAN, 1999), aspirando um papel mais relevante na ONU. E ao mesmo tempo a ONU vive sua crise.

No plano interno a Constituição de 1988 apontou para a criação de um Estado de Bem-Estar, com políticas públicas de cobertura universal de saúde, 
educação, previdência e assistência social. Ampliou ainda mais o reconhecimento de direitos individuais já presentes em outras constituiçóes. Propôs novos canais para o exercício dos direitos políticos, através de conselhos e da iniciativa popular (GONZÁLEZ, 2000).

Porém, ao mesmo tempo que se reconheceram direitos sociais universais, recortou-se o gasto social e diminuiu-se o tamanho do Estado, sob a égide da perspectiva neoliberal, realizando o que Yazbek (1995) denominou "refilatropização do social", transferindo a responsabilidade das políticas sociais para o voluntariado, colocando-se o equilíbrio das contas públicas e o controle inflacionário como objetivos centrais do Governo, independente do partido político ou do presidente da República em exercício. Os eventuais desvios nesta direção foram corrigidos por governos posteriores, como pode ser verificar na agenda de reformas de Michel Temer.

Porém, mesmo neste tipo de reforma permanece a trajetória dúbia do Estado brasileiro. A redução do Estado se dá nas políticas sociais, mas não no aparato repressivo. A garantia de previsibilidade e segurança jurídica deve ser dada a credores externos, mas não necessariamente ao cidadáo que vive na periferia dos grandes centros urbanos.

A desculpa mais frequente para o descumprimento de compromissos assumidos pelo país ao subscrever convençóes internacionais de direitos humanos, presente nos relatórios apresentados por nossos diplomatas perante os órgáos de monitoramento é a estrutura federativa do Estado brasileiro. O Governo Federal estaria tomando todas as medidas a seu alcance para o cumprimento dos tratados, porém as violaçôes continuariam ocorrendo por inércia ou por ação dos governos estaduais (OLIVEIRA, 2000).

Não é demais lembrar que, para um país que teoricamente deixou de ser um regime autoritário há mais de 30 anos para tornar-se uma democracia, não se justifica o fato que o Estado, em suas diversas esferas administrativas, mas principalmente por parte dos estados membros da Federação, é um dos principais violadores de direitos humanos. E para chegar a esta conclusão não é preciso argumentar que fome, desnutrição ou analfabetismo são resultado da inação dos governos. Basta comparar o número de homicídios praticado por policiais com o praticado por outras pessoas. $\mathrm{Ou}$ ainda verificar se em algum estabelecimento prisional do país se cumpre o dispositivo da Constituição de que ao preso é garantida a integridade física e moral. 
Nossa capacidade de indignação muitas vezes é mais aguçada por eventos ocorridos no exterior do que pelos que ocorrem em nossa vizinhança. Provavelmente condiçôes de detenção piores que as de Guantánamo ou da Síria são comuns em delegacias e presídios brasileiros, mas se não houver uma rebelião com mortos, isto não é notícia. Que a CIA leve presos para cativeiros secretos em vôos clandestinos para torturá-los é um absurdo, mas que um preso seja espancado na salinha dos fundos de uma delegacia de interior é considerado normal em nosso país.

\section{Politicas públicas de promoção aos direitos humanos}

Tendo em vista a existência de um extenso conjunto de dispositivos legais, da Constituição Federal, passando pelas Convençôes e Tratados subscritos e incluindo os diversos Estatutos - Criança e Adolescente, Idoso, Juventude -, e Leis Orgânicas Saúde, Educação, Assistência Social - dificilmente pode se concluir que os direitos humanos são descumpridos no Brasil por falta de fundamento legal para sua defesa, o que fica geralmente restrito a novos direitos em construção. Criando estes dispositivos um direito subjetivo do cidadão frente ao Estado, seria de esperar que este buscasse o seu cumprimento de forma sistemática, através da execução de políticas públicas.

Thomas Dye (1987) conceitua política pública simplificadamente como qualquer coisa que o Estado decide fazer ou não fazer. Isto é, não só as açôes planejadas de um Estado se constituem em políticas públicas, mas também a decisão de inação. Mas é possível limitar este conceito ao conjunto de ações realizadas de forma coordenada com o objetivo de um determinado impacto na realidade.

A realização de políticas públicas envolve várias fases, da constatação do problema, passando pela escolha entre as soluçôes possíveis, pela implementação de uma decisão e a avaliação dos resultados (desejável, mas nem sempre realizada) (GRAVITZ e LECA, 1985). Como será discutido abaixo, o momento da tomada de decisões é particularmente sensível.

No Brasil a proposição de políticas públicas tradicionalmente foi segmentada de acordo com a organização da administração pública nos diversos ministérios e secretarias, de acordo com disposiçóes temáticas de grandes áreas como saúde, educação, trabalho ou assistência social, ou público alvo; como crianças, jovens, idosos, mulheres. Não raramente implicando paralelismo que convive com lacunas que ninguém preenche.

Uma política específica para direitos humanos no Brasil surgiu com os Planos Nacionais de Direitos Humanos nos anos 90 (MESQUITA NETO, 1999). O I Plano foi gestado em torno do Ministério da Justiça e tinha como principais objetivos 
elementos ligados ao reconhecimento de direitos, dentro das competências deste ministério. Embora muitos destes objetivos tenham sido alcançados, provocaram apenas mudanças formais (OLIVEIRA, 2000).

A tentativa de realizar uma proposta mais ampla, no II Plano Nacional de Direitos Humanos esbarrou na incapacidade do Ministério da Justiça comprometer outras áreas da administração com sua execução. Aa grande participação de movimentos sociais em sua proposiçáo ampliou o seu conteúdo, mas tornou-o contraditório em muitos pontos. Com as mudanças da Presidência no Governo Federal foi quase esquecido.

O próprio termo Direitos Humanos é associado nos meios de comunicação à defesa de direitos e liberdades individuais. E quando se referem à proteção de direitos individuais nos procedimentos penais, com garantias construídas a partir das declaraçôes de direitos do século XVIII, no entanto, são tratados por radialistas sensacionalistas como "privilégio de bandidos" (CALDEIRA, 2000). Outras políticas públicas, como o SUS, o bolsa-família, ou a Previdência Social, embora diretamente vinculadas à realização de diversos direitos fundamentais, normalmente não são vistos como políticas de direitos humanos.

Com a constataçáo deste quadro de expansão de direitos por via legislativa com retraimento da ação do Estado por argumentos relativos à responsabilidade fiscal ou à prioridade do combate à inflação, se buscam saídas. Uma das vias que tem se tornado cada vez mais comum é a judicialização das demandas frente ao Estado.

\section{É possivel fazer algo? Soluções judiciais e seus limites}

Quando Marshall (1967) apresenta sua clássica conferência sobre os diferentes status de cidadania, ele associa o desenvolvimento da cidadania civil na Inglaterra à existência de tribunais capazes de garanti-la, aos quais os cidadáos têm acesso efetivo. Se pensarmos o Brasil como um Estado de Direito, no qual os direitos subjetivos de cada um dos cidadáos, individualmente ou como grupo social, estão dispostos na lei, a adoção de medidas judiciais pode ser vista como um caminho para a garantia de efetividade destes direitos.

Neste caso os meios a serem empregados, conforme o caso, serão ações individuais ou coletivas, iniciadas por meio de advogados, ou ainda açóes propostas por membros do Ministério Público, estadual ou federal, quando os direitos violados sejam de toda a sociedade. O Ministério Público, com a Constituição Federal de 1988 ampliou seus poderes e campo de atuação. Embora não esteja entre os Poderes 
da República, que ainda são definidos como três, mantendo se o Ministério Público como parte do Poder Executivo, atua como se fosse um, apoiado em sua autonomia funcional e orçamentária.

Com um protagonismo crescente, o Ministério Público, tanto na esfera federal como estadual, deixou o papel anterior, concentrado nas funçóes de acusador nas ações criminais, para atuar cada vez mais em temas relacionados aos direitos do cidadão de forma geral. Além do instrumento da ação civil pública, em muitos casos o Ministério também atua em casos individuais que envolvem crianças ou idosos. Um dos campos em que se destaca este protagonismo é no acesso ao direito à saúde, com a existência de milhares de açôes judiciais em todo o país, envolvendo principalmente pedidos de medicamentos especiais ou acesso a leitos (MARQUES, 2008; MENICUCCI e MACHADO, 2010).

Com a intervenção judicial, o direito das partes envolvidas passa a ser garantido, com o sequestro de recursos públicos para a compra do medicamento, ou a obrigação do Poder Público de pagar por uma vaga no setor privado quando o bem desejado - leito hospitalar, vaga em creche, exame médico, não estiver disponível na rede pública.

\section{Os limites da via judicial e da intervenção do Ministério Público}

Porém a ilusão de uma solução fácil pode trazer uma felicidade momentânea, mas dificilmente poderá assegurá-la contra as investidas da realidade. A judicialização dos conflitos, através do Ministério Público como forma de promover os direitos humanos e ver implementadas políticas públicas encontra diversos limites ou está sujeita a escolhas contraditórias, que levam ao mesmo tempo à sua implementação, mas também podem gerar novas violaçôes, como se discute a seguir.

Primeiro: o membro do Ministério Público quer intervir? O fato de ser sua obrigação funcional a defesa dos direitos do cidadão e a manutenção da legalidade não faz com que, em muitos casos, a pessoa concreta do Promotor, Procurador de Justiça ou da República tenha a possibilidade ou interesse de se envolver em determinada questão.

A limitação do número de quadros leva às substituiçôes em comarcas vizinhas, nas quais a permanência do Promotor é muito pequena para chegar a tomar contato com os problemas locais. Na esfera federal, a presença da Procuradoria da República está limitada às capitais e grandes cidades. 
Por outro lado, mesmo em grandes centros, muitas vezes os temas a serem enfrentados não são motivadores, pois são considerados problemas menores, ou podem levar a um enfrentamento com órgãos de imprensa e opinião pública contrária, como por exemplo, a defesa de condiçóes dignas para apenados. Dois exemplos:

1. Leis federais, como a Lei Orgânica da saúde; a da assistência Social; o Estatuto da Criança e do Adolescente e o do Idoso determinam a necessidade de existência de conselhos municipais, com poderes para gerir fundos em suas respectivas áreas. Em muitos destes casos há milhares de municípios que não tomaram a iniciativa de criá-los, ou o fizeram sem cumprir os requisitos da lei federal. Porque não houve intervençáo do Ministério Público em cada município em que não há conselhos?

2. Recentemente ocorreram uma série de rebeliôes em prisões e ataques à polícia e à população ordenados por facçóes que dominam os presídios, seguidos de retaliaçóes, que no conjunto resultaram em mais de uma centena de mortes. Independente dos mortos serem possíveis acusados ou não dos crimes, as condiçóes em que estavam detidos são sub-humanas. Porque o Ministério Público não aciona o Estado em cada local em que os presídios estão superlotados e controlados por facçóes criminosas?

Segundo: O Ministério Público quer intervir. Isto basta? Se for superado o primeiro passo e estamos diante de um membro do MP motivado, buscando intervir e solucionar o problema, nem sempre isto basta.

Qual a possibilidade de sucesso de uma medida que buscasse assegurar a um indivíduo condenado à privação de liberdade o direito de ser mantido em um estabelecimento compatível com a manutenção de sua integridade física e dignidade? As possibilidades de sucesso são praticamente nulas, seja para o caso individual (salvo se o condenado for uma personalidade do mundo artístico ou econômico), seja para o caso de uma ação do Ministério Público.

Medidas que envolvam a necessidade de investimento do Poder Público serão provavelmente submetidas a inúmeros graus de jurisdição, demorando anos até uma decisão de um Tribunal Superior que provavelmente será tomada, menos levando em conta os argumentos jurídicos e mais os interesses e consequências políticas da decisão. O mesmo STF que julgou constitucional o confisco das contas bancárias do Collor, determinou ao FHC a correção de depósitos do FGTS. 
Os próprios tribunais estão cada vez mais sensíveis à pressão da imprensa e da opinião pública. Uma decisão determinando o uso de recursos públicos para melhorar as condiçóes de presos e, portanto, diminuir seu sofrimento, vai contra a concepção aparentemente dominante na população de que a função da prisão é justamente provocar o suplício.

No caso de solicitações de vagas em hospitais muitas vezes o pedido esbarra na inexistência de vaga na rede, mesmo privada. A decisão judicial não tem o condão de mudar a estrutura física ou de criar médicos e enfermeiros.

Terceiro: O Ministério Público consegue sucesso nas açōes. O resultado é eficaz? Em muitos casos o resultado obtido através da medida judicial torna a lei efetiva, mas ineficaz. Sentenças são instrumentos limitados de transformação do mundo fático quando são necessárias mudanças culturais e envolvimento da sociedade

No caso dos conselhos, mobilizaçóes como a do Estado de Santa Catarina levaram à criação massiva de conselhos, cumprindo formalmente as leis federais. Porém em muitos casos a sociedade local não estava organizada para ocupar este espaço. Portanto surgem conselhos de saúde, da criança ou tutelares desmobilizados ou despreparados para assumir suas funçóes, que passam a existir formalmente, mas com impacto mínimo na realidade.

Não é preciso buscar o exemplo de muitos estados da Federação para constar que decisões que levem ao pagamento de indenizações por precatórios, são altamente ineficazes, muitas vezes sendo o pagamento transferido para os herdeiros das vítimas.

\section{As contradições}

Porém, mesmo que se possam enfrentar estes três limites apontados, a decisão de utilizar a via judicial como meio de implementar açôes na promoção de direitos humanos envolve escolhas contraditórias, que envolvem a opçáo por determinados valores em detrimento de outros.

Primeira: individual $x$ coletivo. Também deve ser levado em conta que não será possível solucionar todos os problemas de violação de direitos humanos por ações judiciais. Mas entre os diversos problemas que devem ser atacados, quais devem ser prioritários?

A judicialização de problemas pode ser um canal adequado para solucionar questóes individuais, como a do fornecimento de um remédio ou a garantia de um leito hospitalar. Embora estas soluçôes pontuais possam ser fundamentais do ponto de vista da sobrevivência da pessoa envolvida, não é isenta de consequências. Um dos argumentos contra as açóes individuais é de que o recurso utilizado para atender a um 
caso individual pode prejudicar a disponibilidade de recursos para atender a outras necessidades do sistema, inviabilizando o atendimento de um número maior de pessoas. Mas podemos preterir o direito de um frente ao direito de um grupo sem um critério utilitarista, que estaria negando a dignidade humana?

A negação do direito individual pode levar à morte de um paciente, pela ausência de um medicamento fundamental ao tratamento. Porém a garantia de um tratamento de alto custo pode negar a outros pacientes o atendimento de atenção básica que indiretamente também pode levar à morte, como na demora do diagnóstico de uma doença como o câncer.

Segunda: decisáo judicial X autonomia do Poder Executivo. Este é um ponto de difícil intersecção entre política, direito e economia. Enquanto esta última define quantidades, as outras duas definem critério de distribuição.

Os recursos disponíveis para o funcionamento do sistema público de saúde dependem de disponibilidade e conveniência. A disponibilidade é limitada por fatores econômicos. A conveniência da distribuição pode ser definida por decisóes oriundas de autoridades políticas ou judiciárias.

Há uma tendência no Brasil das autoridades judiciárias considerarem o limite de suas decisóes sobre a conveniência da distribuiçáo de recursos públicos aos casos individuais. Não seria possível definir sobre condiçôes para alocação de recursos para efetivação de políticas publicas pois isto feriria o princípio da divisão dos poderes, sendo uma ingerência na esfera de atuação do Poder Executivo (GONZÁLEZ, 2011). Embora em um primeiro momento possa se ter a tentação de romper esta barreira com o objetivo de atender ao interesse de cidadáos lesados diante de uma administração pública inerte, a solução não é tão simples.

Não é demais lembrar que dentre os Poderes da República, o Judiciário não possui a legitimação da escolha popular. $\mathrm{O}$ Ministério Público, órgáo que com a autonomia administrativa conquistada se tornou quase um quarto poder, tampouco. Ainda que sejam organismos legítimos do regime democrático, com papéis dispostos na Constituição Federal, não respondem ou são controlados pela soberania popular. E por isso não deveriam se substituir a ela no que se trata de juízos de conveniência política, que vão além da interpretação do caso concreto.

A criação de políticas públicas envolve diretamente a escolha de uma dentro de diversas possibilidades para o enfrentamento de determinado problema. $\mathrm{Na}$ implementação de uma política de saúde como o Promotor que propóe uma ação ou o Juiz que a julga decidiria se é melhor investir em um hospital ou em vários postos 
de saúde? Não se trata de decisão meramente técnica, mas de opção entre concepções políticas diferentes de sistema de saúde. A judicialização disfarça decisóes políticas como se fossem decisões técnicas. Esta situação tende a ser aceita devido à baixa credibilidade da política e dos políticos frente à populaçáo, mas pode ser profundamente antidemocrática.

Terceira: ação do Estado ou ação da Sociedade? A literatura sobre a história política brasileira, como é o caso de Raymundo Faoro (1984) muito explorou o fato que, no Brasil, o Estado precedeu à organizaçáo da Sociedade.

Embora não seja mais esta, de forma geral, a situação do país, ainda são muitos os locais em que as formas organizadas de participação da sociedade são extremamente frágeis e frequentemente dominadas por elites locais que mantém o controle do Estado (Prefeitura ou agências estatais).

A tentação do membro do Ministério Público pode ser a de substituir a lacuna, tornando-se o substituto do corpo social inexistente ou desorganizado. Porém o Ministério Público ou o Poder Judiciário não devem tornar-se agentes políticos que se substituam à sociedade. A tentação das câmaras de televisão e da notoriedade muitas vezes é forte, mas o regime democrático provavelmente funcionará melhor se ela for resistida.

Categorias profissionais por definição não são homogêneas do ponto de vista de concepçôes políticas, como deveriam ser os partidos. A OAB, por exemplo, tem membros que vão da extrema direita à extrema esquerda, democratas e autoritários. $\mathrm{E}$ outras instituiçôes também, provavelmente não sendo diferente o Ministério Público. Quem definiria que valores devem ser defendidos com prioridade?

Qual a decisão a ser tomada quando o tema é controverso na sociedade, como a questão do aborto? Pode um membro do Ministério Público, por suas convicçóes religiosas pessoais, atuar para impedir um pedido de autorizaçáo judicial para aborto ou, se forem opostas, não denunciar um médico que tenha atuado fora das previsóes legais por entender que o fato não deveria ser criminalizado?

Por outro lado, em situaçóes que estruturas tradicionais de poder local oprimem a populaçáo, poderia ser papel do Ministério Público, como agente do Estado, apoiar e fomentar a organização de grupos locais que possam intervir no processo democrático de gestão local, dando apoio às iniciativas existentes, dentro de uma tradição republicana. 


\section{Conclusões}

O objetivo deste trabalho é mais apresentar questionamentos do que respostas prontas. Os limites e contradiçóes apresentados estão ligados à concretude do cotidiano dos que lutam pela promoção dos direitos humanos. Provavelmente não há opção que possa ser considerada correta para todos os casos, uma vez que envolvem opções de valor e concepções de mundo que não se limitam aos dispositivos da Constituição e das leis. A prudência, neste caso, indica que o melhor caminho não é das opçóes absolutas de valor, mas a defesa intransigente de procedimentos também baseados no valor dos direitos humanos.

Entre estes procedimentos está a manutenção de diálogo aberto com todos os setores da sociedade, com a valorizaçáo de espaços democráticos como o dos conselhos e a avaliação permanente das consequências das opçóes feitas. A dificuldade é encontrar um ponto de equilíbrio entre uma suposta neutralidade, descomprometida com os problemas reais que o cercam e os excessos de faccionalismo que podem levar ao oposto - o vanguardista isolado, desconectado da avaliação das possibilidades efetivas de concretizar uma ação.

Neste caminho um dos valores, que foi fundamental para a construção do conceito moderno de direitos humanos, e nunca deve ser esquecido é o da tolerância. Sem tolerância dificilmente haverá plenitude dos direitos humanos (de onde se conclui pela cegueira estúpida e incompatibilidade com a dignidade humana das políticas baseadas no conceito de "tolerância zero").

O Ministério Público certamente se constitui em uma instituição com uma grande contribuição a ser dada na discussão e na implementação de políticas direcionadas à proteção e promoção dos direitos humanos. Mas como qualquer outra política pública, para que esta atuação tenha um mínimo de racionalidade e efetividade, ela deve ser planejada e articulada. Não é concebível uma perspectiva atomista que, baseada em uma interpretação equivocada da autonomia de cada agente do Ministério Público, deixe à decisão para cada um do que deve ou não deve ser feito, gerando açôes descoordenadas ou contraditórias. O Ministério Público deve ser plural às diferentes opções ideológicas, mas não pode aceitar valores incompatíveis como os direitos humanos.

Certamente é um desafio sair dos tranquilos livros de direito, nos quais a soluçâo de todos os problemas do mundo pode ser equacionada pelo raciocínio lógico e por decisóes que fazem sentido no papel, ainda que sejam impossíveis de colocar em prática ou sejam ineficazes ou inefetivas, para tomar contato com o mundo real no 
qual a desnutrição de uma criança não pode esperar o prazo recursal. $\mathrm{O}$ mundo do direito tem muito a aprender com o estudo concreto das políticas públicas. Mas certamente o resultado vale a pena.

Rodrigo Stumpf González é Doutor em Ciência Política pela Universidade Federal do Rio Grande do Sul (UFRGS) e Professor do Programa de Pós-Graduação em Ciência Politica da UFRGS. Bolsista Produtividade em Pesquisa do CNPQ. E-mail: rodrigo.stumpf@ufrgs.br.

\section{Referências}

ARENDT, Hannah. Da Revolução. São Paulo, Ática, 1994.

ARENDT, Hannah. Origens do Totalitarismo. Rio de Janeiro, Ed. Documentário, 1976

BENTHAM, Jeremy. Anarchical Fallacies: being and examination of the Declaration of Rights issued during the French Revolution, 1791. Russell \& Russell, New York: v. 2, 1962.

BOBBIO, Norberto, A Era dos Direitos, Rio de Janeiro, Campus, 1992.

BURKE, Edmund. Textos políticos. México, Fondo De Cultura Económica, 1984.

CALDEIRA, Teresa Pires do Rio. Cidade de Muros- crime, segregação e Cidadania em Sáo Paulo. São Paulo, Edusp, 2000.

CARVALHO, José Murilo de. Cidadania no Brasil. Civilização Brasileira, 2001.

COMPARATO. Fabio Konder. A afirmação histórica dos Direitos Humanos. São Paulo, Saraiva, 1999.

DYE, Thomas. Understanding public policy. New York, Prentice-Hall, 1987.

FAORO, Raymundo. Os donos do poder. 2v. Porto Alegre: Globo, 1984.

GONZÁLEZ, Rodrigo Stumpf. Direitos Humanos e Democracia na Transição Brasileira: OAB, CNBB e Anistia Internacional. Porto Alegre, UFRGS, 1994.

GONZÁLEZ, Rodrigo Stumpf. Democracia e conselhos de controle de politicas públicas - uma análise comparativa. 2000, 280f. Tese (Doutorado em Ciência Política). Programa de Pós-Graduação em Ciência Política, Universidade Federal do Rio Grande do Sul, Porto Alegre, 2000. 
GONZÁLEZ, Rodrigo Stumpf. A Retórica dos Direitos Humanos In: STRECK, Lenio (Org.). Constituição, sistemas sociais e hermenêutica. Porto Alegre: Livraria do Advogado, 2007. p. 165-180.

GONZÁLEZ, Rodrigo Stumpf. A política de promoção aos direitos humanos no Governo Lula. Revista Debates, v. 4, n. 2, p.10- 18, 2010.

GONZÁLEZ, Rodrigo Stumpf; LENTZ, Rodrigo. Qual será a verdade do jeitinho brasileiro? Perspectivas sobre a Comissão Nacional da Verdade do Brasil. Ciências Sociais Unisinos, v. 48, n. 2, p. 130-138, 2012.

GONZÁLEZ, Rodrigo Stumpf. Racionalidades conflitantes nas decisões dos Poderes Executivo e Judiciário sobre políticas públicas. In: XXVIII Congresso Internacional da Associação Latino-Americana de Sociologia, 2011, Recife. Memorias Congreso ALAS. Recife: Alas, 2011.

GRAWITZ, Madeleine e LECA, Jean. Traité de Science Politique vol 4. - Les politiques publiques. Paris, PUF, 1985.

LOPES, Júlio Aurélio Vianna. A invasão do direito: a expansão jurídica sobre o Estado, o mercado e a moral. FGV Editora, 2005.

MARSHALL, T. H. Cidadania, Classe Social e Status. Rio de Janeiro, Zahar, 1967.

MARQUES, Silvia Badim. Judicialização do direito à saúde. Revista de Direito Sanitário, v. 9, n. 2, p. 65-72, 2008.

MENICUCCI, Telma Maria Gonçalves; MACHADO, José Angelo. Judicialization of health policy in the definition of access to public goods: individual rights versus collective rights. Brazilian Political Science Review (Online), v. 5, n. SE, p. s/d, 2010.

MESQUITA NETO, Paulo de. O papel do Governo Federal no Controle da Violência: O Programa Nacional de Direitos Humanos 1995-1997- In: AMARAL JÚNIOR, Alberto do; PERRONE-MOISÉS, Cláudia (Orgs.) O Cinqüentenário da Declaração Universal dos Direitos do Homem. São Paulo, Edusp, 1999. p. 353-373.

OLIVEIRA, Isabel Ribeiro. Cidadania e política de direitos humanos no Brasil. Contemporaneidade e Educação, v. 5, n. 8, p. 56-73, fev. 2000.

PECES-BARBA MARTINEZ, Gregorio. Derecho y derechos fundamentales. Madrid, Centro de Estudios Constitucionales, 1993

PEREZ LUÑO, Antônio Enrique. Derechos humanos, Estado de derecho y constitución. Madrid, Tecnos, 1995.

PIOVESAN, Flávia. Direitos humanos globais, justiça internacional e o Brasil. In: AMARAL JÚNIOR, Alberto do; PERRONE-MOISÉS, Cláudia (Orgs.). O 
98 | Rodrigo Stumpf González

Cinquentenário da Declaração Universal dos Direitos do Homem. São Paulo, Edusp, 1999. p. 239-253.

TRINDADE, Antonio Augusto Cançado. Tratado de direito internacional de direitos humanos. Porto Alegre, Sergio Fabris Ed. 1997.

VIANNA, Luiz Werneck. A judicialização da política e das relaçôes sociais no Brasil. Editora Revan, 1999.

YAZBEK, Maria Carmelita. A política social brasileira nos anos 90: a refilantropização da questão social. Cadernos de textos da I Conferência Nacional de Assistência Social. Brasília, CNAS, outubro de 1995. p. 15-24.

Texto recebido em 30 de março de 2017. Aprovado em 03 de abril de 2017. 